\title{
What is Single-Payer Health Care? A Review of Definitions and Proposals in the U.S.
}

\author{
Jodi L. Liu, PhD, MSPH' and Robert H. Brook, MD, SCD ${ }^{1,2}$ \\ 'RAND Corporation, Santa Monica, CA, USA; ${ }^{2}$ University of California, Los Angeles, Los Angeles, CA, USA.
}

\begin{abstract}
BACKGROUND: Single-payer systems have been proposed as a health care reform alternative in the United States. However, there is no consensus on the definition of single-payer. Most definitions characterize single-payer as one entity that collects funds and pays for health care on behalf on an entire population. Increased flexibility for state health care reform may provide opportunities for state-based single-payer systems to be considered.

OBJECTIVE: To explore the concept of single-payer and to describe the contents of single-payer health care proposals.
\end{abstract}

DESIGN: We compared single-payer definitions and proposals. We coded the proposal text for provisions that would change how the health care system functions and could impact health care access, quality, and cost.

MAIN MEASURES: The share of proposals that include changes to the financing, pooling, purchasing, and delivery of health care; and possible impact on access, quality, and costs.

KEY RESULTS: We identified 25 proposals for national or state single-payer plans from journal and legislative databases. The proposals typically call for wide-ranging reform; nearly all include changes across the financing, pooling, purchasing, and delivery of health care services. Many provisions aiming to improve access, quality, and cost containment are also included, but the proposals vary in how they plan to achieve these improvements. Common provisions are related to comprehensive benefits, patient choice of providers, little or no cost sharing, the role of private insurance, provider guidelines and standards, periodic reviews of the benefits package, electronic medical records and billing, prescription drug formulary, global budgets, administrative cost thresholds, payment reform and studies, and the authority to implement cost-containment strategies.

CONCLUSIONS: Single-payer systems are heterogeneous. Acknowledgment of what is considered as singlepayer and the characteristics that are variable is important for nuanced policy discussions on specific reform proposals.

KEY WORDS: health care reform; single payer; health insurance.

Electronic supplementary material The online version of this article (doi:10.1007/s11606-017-4063-5) contains supplementary material, which is available to authorized users.

Received October 26, 2016

Revised March 13, 2017

Accepted April 10, 2017

Published online May 10, 2017
J Gen Intern Med 32(7):822-31

DOI: $10.1007 / \mathrm{s} 11606-017-4063-5$

(C) Society of General Internal Medicine 2017

\section{INTRODUCTION}

As a result of the November 2016 elections, the future of health care reform in the U.S. is unclear. President Donald Trump and Congressional Republicans have vowed to repeal and replace the Affordable Care Act (ACA). Although details of the replacement plan are uncertain, Republican plans frequently aim to give states more flexibility to manage health care programs. As national health care policies evolve, states will be faced with decisions on what they can do to provide health insurance and access to care for their residents, particularly if Medicaid expansion and insurance marketplace subsidies are eliminated.

One alternative financing plan in which states have shown periodic interest is a single-payer health care system. National health insurance administered by a single payer has been considered in the U.S. since the early 1900s, but has been a polarizing issue, with staunch advocates and strong opposition. $^{1,2}$ In 2010, Vermont passed legislation for a state-based single-payer system under a Section 1332 waiver of the ACA. ${ }^{3}$ However, the plan stalled at the end of 2014, with the governor's office citing higher than expected tax estimates needed to finance the system. ${ }^{4} 5$ Other bills have been periodically proposed at the federal and state levels, although few have garnered substantial support. Nonetheless, Senator Bernie Sanders's 2016 presidential campaign ${ }^{6}$ drew renewed attention to single-payer health care. In November 2016, Colorado residents voted to reject a ballot measure for a state single-payer system. ${ }^{7}$ In February 2017, the California legislature introduced a bill stating an intent to establish a state single-payer system.

Although single-payer plans have been continually proposed in the U.S., the term is used with different meanings. Single-payer is often used in political rhetoric, with some using it to refer to the Canadian health care system, and others using it synonymously with "socialized medicine" and other variations. ${ }^{8}$ Canada has a single-tiered, tax-financed system that is administered by provinces, and care is delivered by private non-profit providers. In contrast, socialized medicine typically refers to systems such as the National Health Service 
in the United Kingdom, which is a tax-financed system with mostly government-run health facilities.

In this work, we compare single-payer definitions and health care reform proposals involving a single payer in the U.S. We assess the breadth of proposal provisions across health care system functions. To assess how the provisions aim to improve the health care system, we describe provisions related to access, quality, and costs. Clearly defined policy proposals would inform the debate on whether a single-payer system could be a viable reform alternative in the U.S.

\section{METHODS}

We conducted searches on legislative and academic databases to identify single-payer proposals; searches were conducted between May and December 2014. We used the following search terms: single payer, Medicare for all, national health insurance, Beveridge model, universal coverage, publicly funded, United States, America, definition, proposal, plan, and bill. We excluded search results from earlier than 1990, because single-payer in its current usage appeared in the early 1990s. ${ }^{9}$

The search for single-payer bills on Congress.gov, Scout, and WestlawNext yielded 262 results. We reviewed titles and bill summaries to determine inclusion. Resolutions were excluded. If a legislature produced multiple versions of a bill, we included the most recent version. We identified additional state legislation via Google searches and reference mining. This resulted in three federal and 20 state bills.

Literature searches on PubMed, Scopus, and Academic Search Complete yielded 2498 articles. We excluded articles discussing only legislative proposals, politics, stakeholder perspectives, implementation, or reform in other countries. Title and abstract screening resulted in 29 articles. A full-text review resulted in two proposals that were not legislative bills.

In this paper, we refer to journal articles, bills, and Vermont's Act 48 collectively as single-payer proposals.

\section{Assessment of proposals}

We assessed the breadth of the proposals by the inclusion of provisions relating to health care system functions. The conceptual framework, adapted from Kutzin ${ }^{10}$ shows four main functions: collection of funds, pooling of funds, purchasing of services, and provision of services (Fig. 1). Fund collection includes the types of revenue sources and contribution levels. Funds are pooled for the eligible population. Purchasing includes provider payment, such as fee-for-service and institutional budgets. The provision of services includes specifications of covered services and provider eligibility.

To evaluate how the provisions would improve the health care system, we considered linkages to access, quality, and cost containment. As the impacts of the provisions have not been scored, we coded the intent and plausible impact based on the proposal text. The first reviewer (JL) coded sections

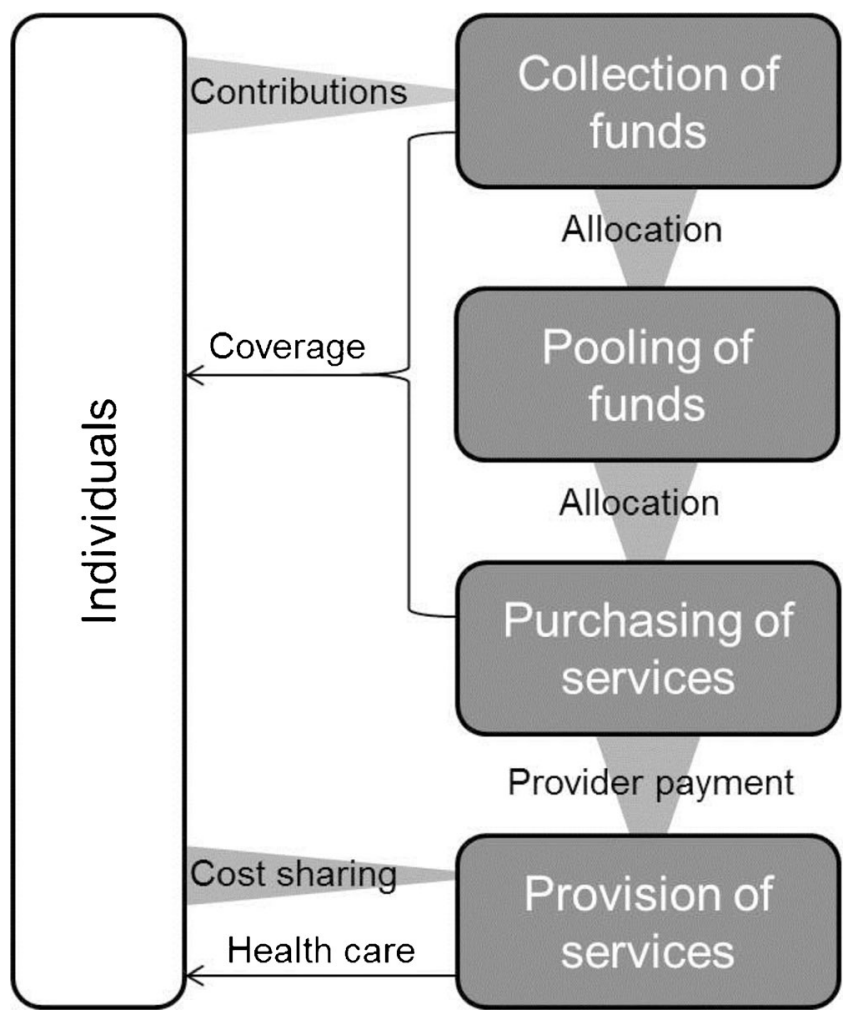

Figure 1 Framework of health care system functions. Source: Adapted from Kutzin (2001).

relating to access, quality, and cost. Text was marked as "access" if related to insurance coverage, benefit design, and provider access or availability. Text was marked as "quality" if related to systems or procedures that could impact quality of care through changes in provider behavior or standardization. Text was marked as "cost" if related to cost-control strategies and systems or procedures affecting prices or payment. We allowed text to be coded as more than one category. An additional tag was used to mark the text with unclear assignment. For text marked as unclear, a second reviewer (RB) independently coded the text. The reviewers discussed and reconciled the assignment. JL documented the provisions into a matrix and tallied the results to identify common themes. RB reviewed the full set of final assignments.

\section{Limitations}

The search methodology was intended to capture a range of recent proposals but was not exhaustive. Proposals involving a single payer but not explicitly including the term may have been missed during screening.

The manual coding was subject to human error. In addition, the initial extraction of relevant text was conducted by one reviewer. While a second reviewer checked the full set of final assignments, it is possible some relevant text was omitted from the initial extraction.

The coding of access, quality, and cost was based on intent and plausible impact of the provisions rather than a formal scoring of impact. The assessment relied on the detail 
contained in the proposals. An omission of a provision may indicate a lack of detail rather than a deliberate design choice. Furthermore, an omission does not preclude adoption of a measure at a later time; many proposals indicate that some details would be determined at a later date after additional studies.

\section{RESULTS}

\section{Definitions}

The term single-payer originated in the early 1990 s to differentiate the Canadian health care system, which has government financing and private delivery, from that of the United Kingdom, where the government is responsible for both financing and delivery. ${ }^{9}$ It has since evolved to often describe financing by a single public entity irrespective of the type of delivery.

Table 1 shows single-payer definitions listed from narrow to broad. Most describe the payer. Half the definitions describe the eligible population (e.g., universal), plan (e.g., comprehensive, cost sharing), and financing (e.g., taxes). Components included in one or two definitions are provider payment, cost controls, administrative costs, and the role of private insurance.

Although the single payer is typically conceived of as a public entity, some definitions do not restrict the payer to government only. Slee and Slee include the possibility of an insurance company as the payer. ${ }^{11}$ Their definition is also inclusive of subnational systems, which is descriptive of the Canadian system decentralized to local payers for each province/territory. Similarly, Kutzin describes flexible geography and public/private sector affiliation, while specifying coverage of the main service package. ${ }^{10}$

In a 2009 special issue on single-payer concepts, several authors note the lack of consensus on what is meant by singlepayer. ${ }^{8}$ This review builds upon the prior work by identifying key characteristics across the numerous definitions, and puts them in context with proposals. Several definitions restrict the scope of a single payer within a broader system. Oliver describes a single collector that can have multiple local payers. ${ }^{12}$ Tuohy suggests using the population covered, service category, and jurisdiction to describe a single-payer system within a broader hybrid. ${ }^{9}$ White describes citizens in a geographic area, who make mandatory contributions and receive coverage for medical and hospital care. ${ }^{13}$ Going beyond population, services, and financing, Blewett includes the possibility of simplified administration and explicit cost controls. ${ }^{14}$ Glied refers to single-payer advocates who call for little or no cost sharing and private, non-for-profit providers. ${ }^{15}$ Glied also describes single-payerness based on the number of revenue sources, use of private insurance, and subnational financing. Stone calls single-payer a rhetorical term to avoid the term "social insurance. $" 16$.

\section{Proposals}

Table 2 shows the 25 proposals reviewed. The Physicians for a National Health Program (PNHP) proposal ${ }^{17}$ and the HealthInsurance Solution ${ }^{18}$ are very different approaches. PNHP recommends universal comprehensive benefits without cost sharing. The Health-Insurance Solution would have incomerelated (means-tested) deductibles and out-of-pocket maximums to prevent catastrophic financial losses for all citizens and legal residents not covered by Medicare or Medicaid. Medicare and Medicaid would continue, and private insurance would not be restricted.

The three federal bills were the Medicare For All Act, American Health Security Act, and National Health Insurance Act. ${ }^{19-22}$ Versions of these bills have been repeatedly introduced in Congress. All three propose coverage of comprehensive benefits. The Medicare for All Act and the American Health Security Act are similar and include combinations of taxes, payment reform, no cost sharing, and banning of private insurance duplicating the single-payer plan.

We identified 20 state proposals from across the country (6 Northeast, 3 South, 4 Midwest, 7 West). ${ }^{4,}{ }^{23-37}$ All offer universal coverage of comprehensive benefits, except the Connecticut bill, which is solely a statement of purpose. The proposals vary in the level of detail and the extent that provisions would be determined at a later date, as well as how cost sharing, provider choice, supplemental insurance, quality of care, and cost controls are addressed.

We compared the proposal contents to components of single-payer definitions (Table 2). All the proposals indicate the payer and relevant geography. All except the Connecticut bill specify the eligible population, benefits, and financing. Most discuss the types of providers that could participate in the system and how they would be paid. Administrative costs, cost controls, and the role of private insurance are discussed in many proposals, but as with the definitions, these components are not consistent across proposals.

In the following sections, we describe the breadth of the proposals and access, quality, and cost provisions. Based on key distinguishing features, we categorize the proposals as traditional, cost sharing, high-level, and catastrophic (Table 2 and online Appendix Tables A.1-.4). The traditional proposals provide coverage of comprehensive benefits with no cost sharing (free care for all). The cost-sharing proposals also offer comprehensive benefits but may allow cost sharing; in addition, these proposals tend to be cost-conscious and would study or later implement cost-containment strategies. The high-level proposals are less detailed and contain fewer access, quality, and cost provisions. The sole catastrophic proposal diverges from the others by offering income-related benefits.

\section{Breadth Across Health Care System Functions}

Figure 2 shows the percentage of proposals containing provisions relating to health care system functions. Nearly 


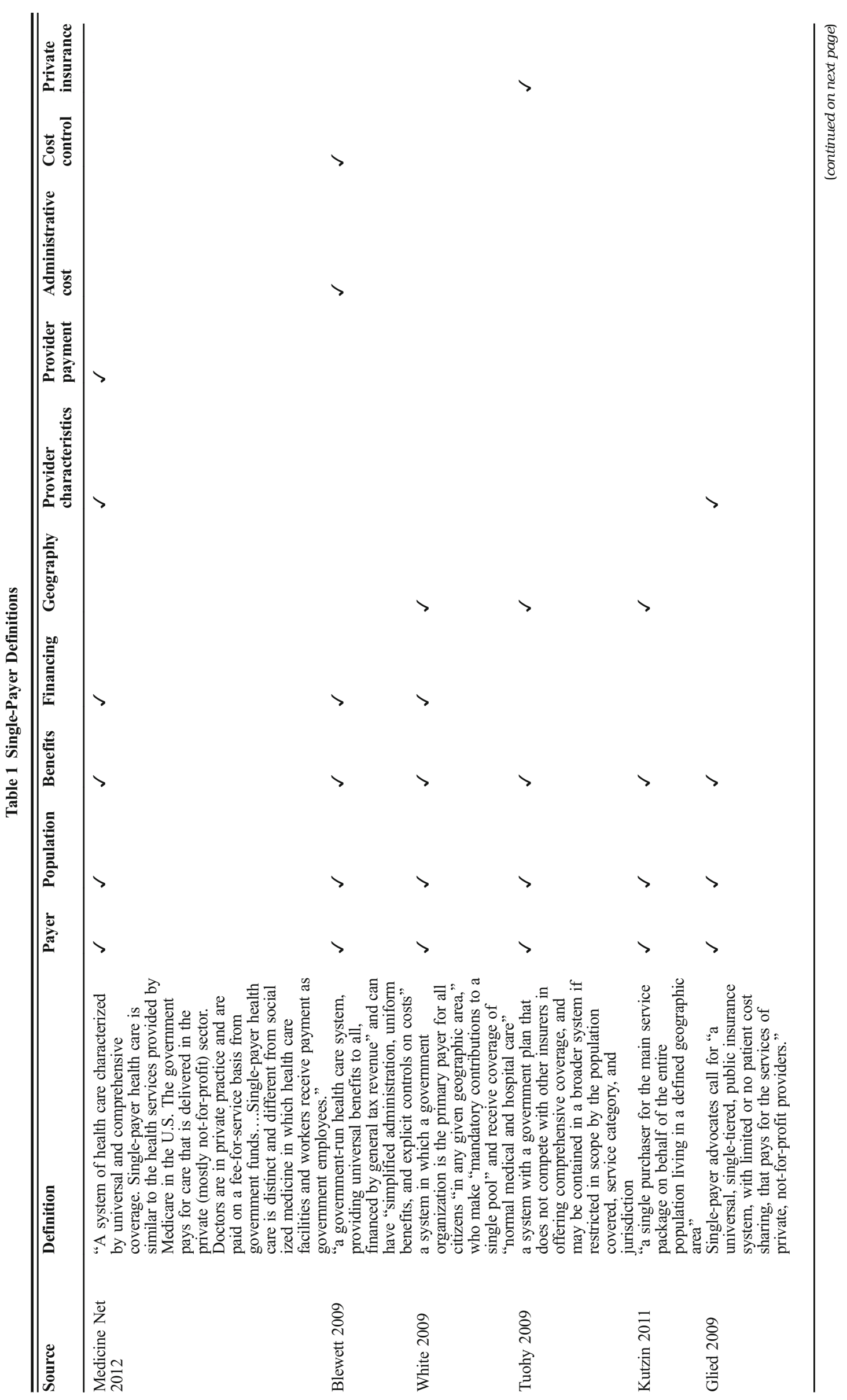




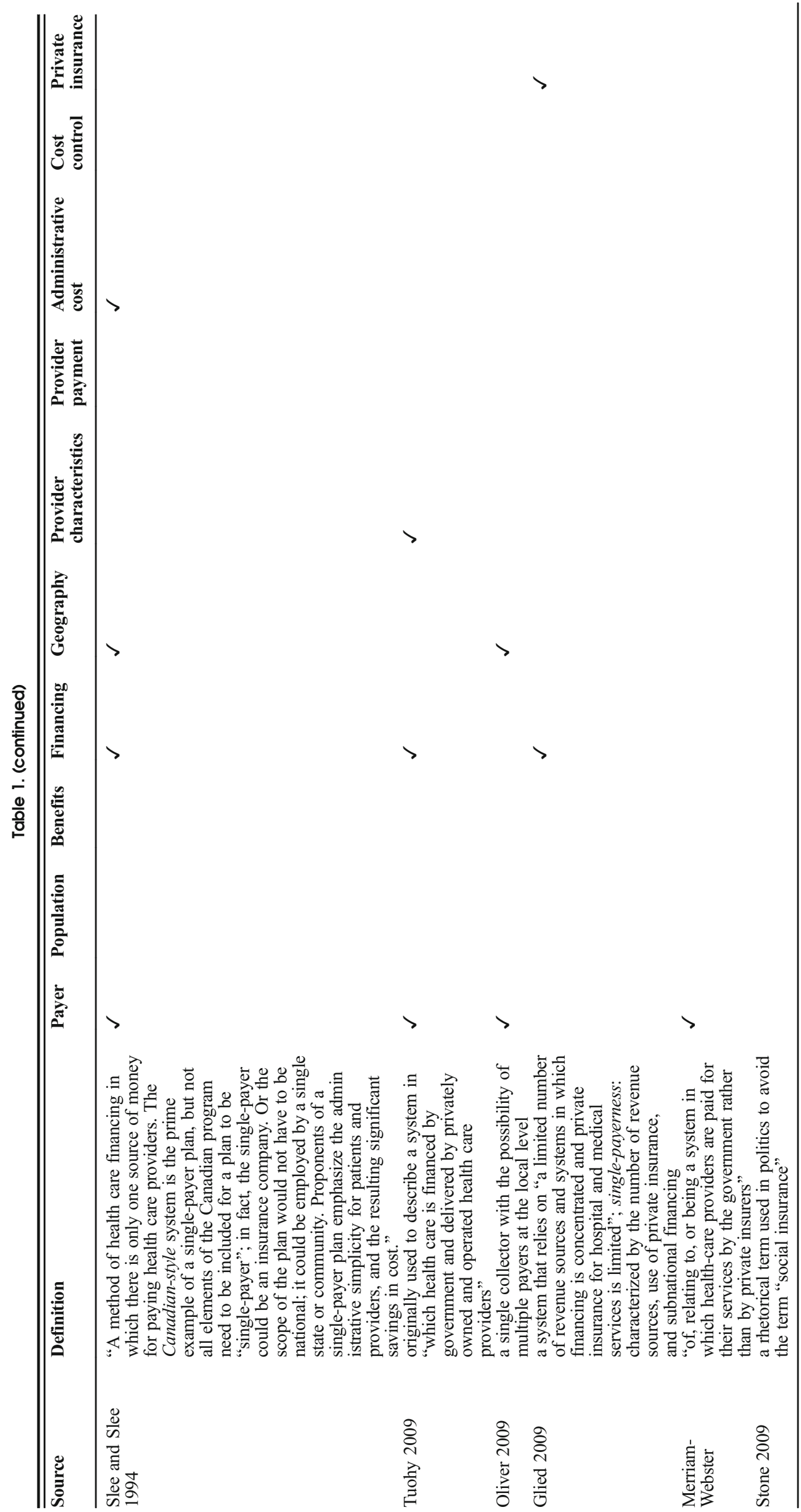




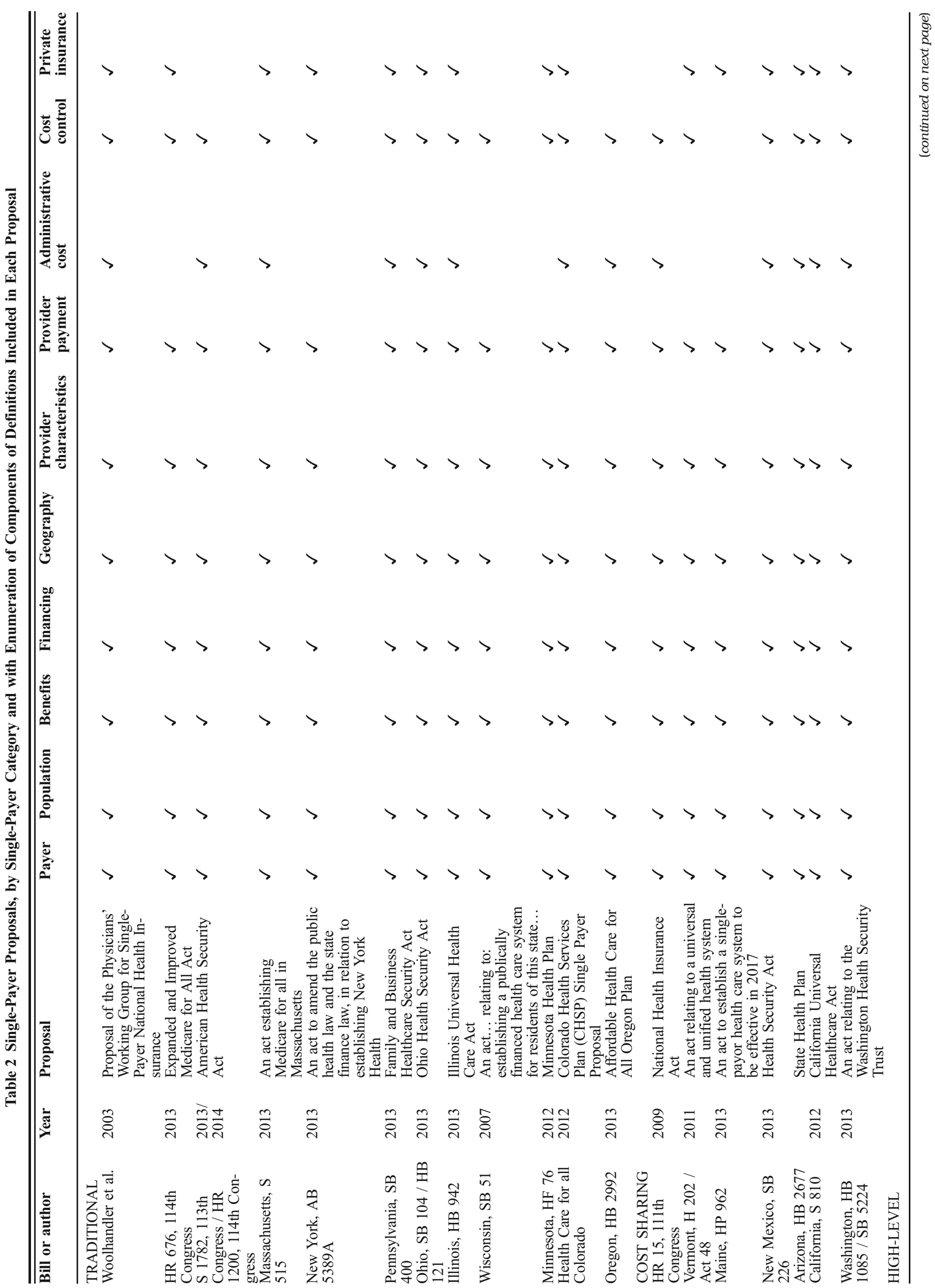



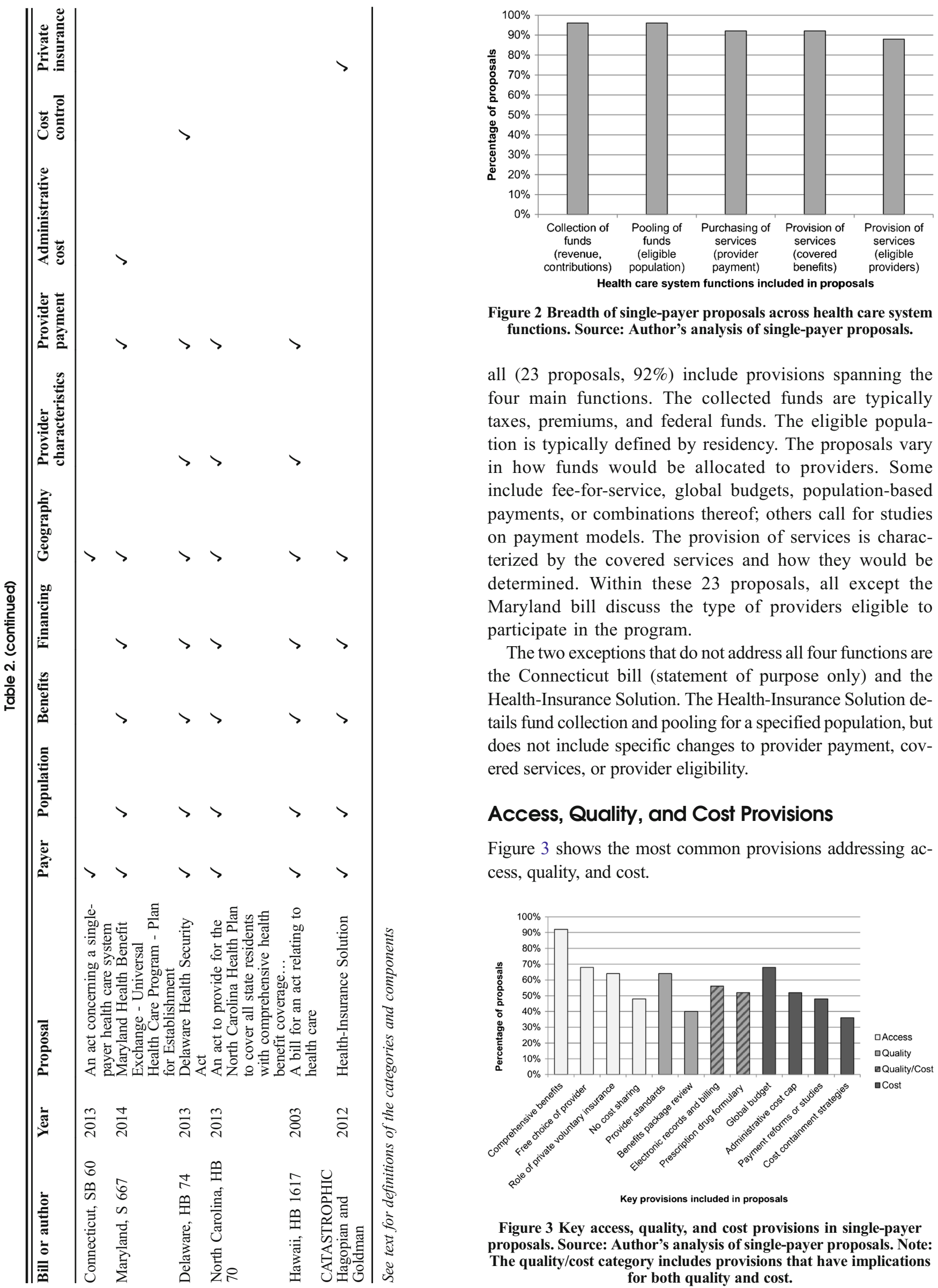

Figure 2 Breadth of single-payer proposals across health care system functions. Source: Author's analysis of single-payer proposals.

all (23 proposals, 92\%) include provisions spanning the four main functions. The collected funds are typically taxes, premiums, and federal funds. The eligible population is typically defined by residency. The proposals vary in how funds would be allocated to providers. Some include fee-for-service, global budgets, population-based payments, or combinations thereof; others call for studies on payment models. The provision of services is characterized by the covered services and how they would be determined. Within these 23 proposals, all except the Maryland bill discuss the type of providers eligible to participate in the program.

The two exceptions that do not address all four functions are the Connecticut bill (statement of purpose only) and the Health-Insurance Solution. The Health-Insurance Solution details fund collection and pooling for a specified population, but does not include specific changes to provider payment, covered services, or provider eligibility.

\section{Access, Quality, and Cost Provisions}

Figure 3 shows the most common provisions addressing access, quality, and cost.

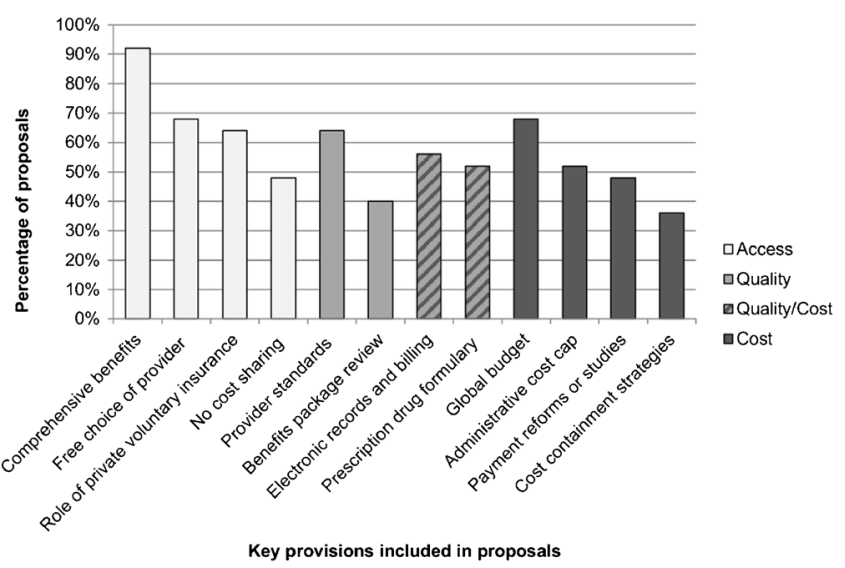

Figure 3 Key access, quality, and cost provisions in single-payer proposals. Source: Author's analysis of single-payer proposals. Note: The quality/cost category includes provisions that have implications for both quality and cost. 
Access. With the Health-Insurance Solution and the Connecticut bill constituting the two exceptions, 23 proposals $(92 \%)$ would provide eligible residents with comprehensive benefits. "All medically necessary health care" is mentioned in 11 proposals (44\%). Twelve proposals (48\%) specify no cost sharing (deductibles, copayments, and coinsurance); six proposals leave cost sharing to be determined following analyses. In 17 proposals (68\%), patients have free choice of providers; this extends only to primary care providers in five proposals that require referrals for specialty care.

The role of private voluntary health insurance is discussed in 16 proposals $(64 \%)$, ranging from prohibiting substitutive and/or supplementary insurance to no mention of restrictions. Of these, nine proposals allow some type of private insurance. None prohibit complementary private insurance.

Other access-related provisions include the establishment of an enrollment system (e.g., with minimal language and literacy barriers), ensuring adequate resources in underserved areas, addressing state issues (e.g., reimbursement for out-of-state services, reciprocity agreements with other states), and monitoring access (e.g., annual reviews of unmet needs).

Quality. Health care provider guidelines, standards, and monitoring are included in 16 proposals $(64 \%)$. Ten proposals $(40 \%)$ include review and modification of the benefits package based on value and safety; four proposals $(16 \%)$ mention reducing the use of ineffective or inappropriate care.

The establishment of electronic systems for records and payments has implications for both quality and cost, and is included in 14 proposals $(56 \%)$. Also spanning quality and cost, 13 proposals $(52 \%)$ include formularies for prescription drugs and medical supplies to allow for standardized use of efficacious and cost-effective medications and to support bulk purchasing and price negotiations.

Other quality-related provisions include studies on new models of care, ensuring a workforce able to deliver quality care (including adequate payments to support the workforce), care coordination, promotion of preventive care, and public reporting of quality ratings and prices.

Cost. The most common cost provision is global budgets for total expenditures (17 proposals; 68\%). The global budget is typically set based on prior-year expenditures and projected growth in gross domestic (or state) product. A threshold for administrative costs is set as a proportion of total expenditures in 13 proposals $(52 \%)$.

Provider payment is addressed in 12 proposals (48\%): nine would have hospitals and health maintenance organizations operating under institutional global budgets, and three mention additional studies of payment models. Nine proposals (36\%) specify the authority to implement cost-containment strategies if necessary; five proposals (20\%) plan to study cost-containment approaches. Other cost-related provisions include medical fraud investigations, migration effect studies, and eliminating the tax exclusion for employer-sponsored insurance premiums.

\section{DISCUSSION}

Although single-payer is typically defined primarily as a financing mechanism for universal coverage, legislators and researchers have proposed single-payer systems as comprehensive reform with changes across the health care system functions and aims to improve access, quality, and cost containment. Many common provisions are not unique to singlepayer-for example, establishing provider standards, formularies, and electronic records-but could potentially be achieved to a greater extent or at a broader scale with a single-payer system.

Meaningful policy discussions involving single-payer may be aided by a common understanding. We suggest following Tuohy's approach in defining single-payer within a hybrid of subnational systems (characterized by a specified population, service categories, and jurisdiction), because it captures widely what people mean by single-payer, while including common characteristics by which systems may differ. Subnational systems for specific populations such as Medicare or statebased systems could be considered single-payer within the broader U.S. system.

Single-payer is not a one-size-fits-all approach. Proposals are heterogeneous and provisions can be modular. To achieve national universal coverage, policymakers may consider the catastrophic type of proposal as a more conservative approach than the traditional single-payer. Means-tested and highdeductible plans both provide a form of catastrophic coverage; however, means-testing differs by providing lower cost sharing to lower-income households.

States considering single-payer would face numerous decisions about benefit design, financing, payment mechanisms, and other features. The traditional proposal with no cost sharing was the most common type we reviewed. However, we found several state proposals that allow cost sharing to encourage the use of effective services or if cost controls were needed. The cost sharing proposals also frequently featured cost-conscious provisions such as the authority to implement cost-containment strategies if needed and further study of cost controls and payment mechanisms. These cost provisions may be even more likely after Vermont's single-payer experience, which had wide variation in cost saving assumptions that contributed to high estimated taxes needed to finance the system. ${ }^{5}$ To advance, a proposal would likely need to address issues beyond those specified in the high-level proposals.

Although cost-containment provisions are frequently in proposals, strategies are often unspecified. Single-payer systems are thought to reduce costs through lower administrative costs and prices, ${ }^{38,39}$ but the extent and time frame of these reductions is unknown. Bulk drug purchasing by a single 
payer able to negotiate prices may help reduce costs, although the magnitude possible at a large scale is uncertain. In addition, price reductions may be at the expense of medical research and innovation and may require initial investments. ${ }^{40}$, ${ }^{41}$ Similar to the ACA, a single-payer system could employ a host of different approaches to cost containment and payment reform. These uncertainties contribute to substantial variation in cost analyses of proposals. ${ }^{5}$

Single-payer proposals face many of the same political and implementation challenges as the ACA, which are typical of any system-wide reform. ${ }^{42}$ For example, the benefits package and provider reimbursement must be determined. The proposals frequently have an expert board/committee to determine covered services, benefit design, budgets, and payment rates. These boards are intended to ensure that effective, appropriate care is provided and reimbursed through the system. However, they are also often perceived as taking away patient and provider choice through a form of rationing.

States face additional implementation challenges. Under Section 1332 of the ACA, states can apply for a federal waiver to pursue alternative reform, but are required to provide coverage as comprehensive and affordable as the health insurance marketplaces. ${ }^{43}$ States could have increased opportunities to pursue alternative reform pathways if the ACA is repealed and Medicaid block grants allow federal funds to be more easily redirected. States must also address how to reimburse services obtained by residents temporarily out of state, and determine eligibility and contributions of non-residents who work in the state.

Although universal coverage is an important step, it does not guarantee access to care. There have been concerns about narrow provider networks restricting access and lowering the perceived quality of plans. ${ }^{44,45}$ Although provider networks would not be an issue if patients had free choice of providers, access could be restricted if provider supply is inadequate. Opponents of single-payer systems often point to waiting times in single-payer systems in other countries. ${ }^{46-49}$ The system capacity required to meet the needs of all residents depends in part on provider participation in the program.

A key factor in provider supply is payment policy in the single-payer system. Many proposals describe payment arrangements such as fee-for-service with rates negotiated between a board and provider groups, and salaried in institutions with global budgets. Several proposals would develop new payment models through demonstration projects. However, it is unclear how providers will respond to payment changes due to rate negotiations, global budgets, or other payment models. Furthermore, health care providers may have the option of participating in the single-payer system and/or a parallel private market.

The proposals frequently mention private insurance options but vary in the types allowed. Substitutive insurance duplicating the single-payer plan is frequently banned; restrictions on other types are less common. Complementary insurance (for services not covered by the single-payer plan) or supplementary insurance (for faster or improved access to the same services as those covered by the single-payer plan) are common in other countries. ${ }^{50,51}$ For example, Canadians often purchase complementary coverage for prescription drugs and dental services. ${ }^{51}$ Among U.S. Medicare beneficiaries, "wraparound" (or supplemental) plans are widespread ${ }^{52}$; however, estimated spending by Medigap enrollees is 27-45\% higher than those without Medigap. ${ }^{53,54}$ While complementary insurance covers a service gap excluded from statutory benefits, supplementary insurance creates a parallel risk pool for the same services. ${ }^{50}$ Allowing coverage for faster access (i.e., "jumping the queue") or private care by those who can pay may create inequities in access with a two-tiered system. ${ }^{13}$ Differences in payment arrangements could result in providers favoring one system over the other, leading to inadequate provider supply in the latter system.

\section{CONCLUSION}

Many states have proposed legislation to establish a singlepayer health care system. The majority of the proposals call for sweeping changes across the health care system and aim to improve access, quality, and cost containment. Within the structure of a single-payer system, there are many critical characteristics that are variable. Section 1332 of the ACA provides states with an opportunity to design and implement alternative reform within the boundaries of equivalent coverage and affordability, and states may have increased flexibility under alternative plans if the ACA is repealed.

As the political conversation on how to improve the health care system continues, it is helpful to have an understanding of what is meant by single-payer and the content of proposals. Further research on cost-containment strategies and provider responses to payment reforms would inform cost analyses and support policymakers on future health care reform decisions.

Contributors: We thank Jeffrey Wasserman and Christine Eibner for useful comments.

Funders: This work was generously supported by an anonymous gift to RAND Health

Prior Presentations: None.

Corresponding Author: Jodi L. Liu, PhD, MSPH; RAND Corporation, 1776 Main Street, P.O. Box 2138, Santa Monica, CA 90407-2138, USA (e-mail: jodiliu@rand.org).

\section{Compliance with Ethical Standards:}

Conflict of Interest: Dr. Robert H. Brook owns stock in United Health Group. All remaining authors declare that they do not have a conflict of interest.

\section{REFERENCES}

1. Harrison B. A historical survey of national health movements and public opinion in the United States. JAMA. 2003;289(9):1163-4.

2. Kaiser Family Foundation. National health insurance - a brief history of reform efforts in the U.S. Menlo Park, CA Kaiser Family Foundation; 2009. 
3. Vt. Acts \& Resolves 48. An act relating to a universal and unified health system. 2011.

4. State of Vermont Agency of Administration, Health Care Reform. Green mountain care: a comprehensive model for building Vermont's universal health care system. Montpelier, VT; 2014.

5. McDonough JE. The demise of Vermont's single-payer plan. N Eng $\mathrm{J}$ Med. 2015;372(17):1584-5.

6. Sanders B. Medicare for All: leaving no one behind 2016. 2016. Available at http://berniesanders.com/wp-content/uploads/2016/01/Medicarefor-All.pdf. Accessed 9 April 2017.

7. Hanel J, Downs A, Clark B, Foster C, Goeken D, Lueck M, et al. ColoradoCare: An independent analysis. Denver, CO: Colorado Health Institute; 2016.

8. Sparer MS, Brown LD, Jacobs LR. Exploring the concept of single payer. J Health Polit Policy Law. 2009;34(4):447-51.

9. Tuohy $\mathbf{C H}$. Single payers, multiple systems: the scope and limits of subnational variation under a federal health policy framework. J Health Polit Policy Law. 2009;34(4):453-96.

10. Kutzin J. A descriptive framework for country-level analysis of health care financing arrangements. Health Policy. 2001;56(3):171-204.

11. Slee VN, Slee DA. Health care reform terms: An explanatory glossary of words, phrases, \& acronyms used in today's U.S. "health care reform" movement. Second edition. St. Paul, MN: Tringa Press; 1994.

12. Oliver A. The single-payer option: A reconsideration. J Health Polit Policy Law. 2009;34(4):509-30.

13. White J. Gap and parallel insurance in health care systems with mandatory contributions to a single funding pool for core medical and hospital benefits for all citizens in any given geographic area. J Health Polit Policy Law. 2009;34(4):543-83.

14. Blewett LA. Persistent disparities in access to care across health care systems. J Health Polit Policy Law. 2009;34(4):635-47.

15. Glied S. Single payer as a financing mechanism. J Health Polit Policy Law. 2009;34(4):593-615.

16. Stone D. Single payer: good metaphor, bad politics. J Health Polit Policy Law. 2009;34(4):531-42.

17. Woolhandler S, Angell M, Young QD, Himmelstein DU. Proposal of the Physicians' Working Group for Single-Payer National Health Insurance. JAMA. 2003;290(6):798-805.

18. Hagopian K, Goldman D. The Health-Insurance Solution. National Affairs. 2012;13:95-111.

19. Expanded \& Improved Medicare For All Act, H.R. 676, U.S. House of Representatives, 114th Cong., 1st Sess. 2015.

20. American Health Security Act of 2013, S. 1782, U.S. Senate, 113th Cong., 1st Sess. 2013

21. American Health Security Act of 2015, H.R. 1200, U.S. House of Representatives, 114th Cong., 1st Sess. 2015.

22. National Health Insurance Act, H.R. 15, U.S. House of Representatives, 111th Cong., 1st Sess. 2009.

23. H.B. 2677, 48th Leg., 1st Reg. Sess. Sess. Ariz. 2007.

24. S. 810, 2012 Leg. Sess. Cal. 2012.

25. H.B. 74, 147th Gen. Assem. Sess. Del. 2013.

26. H.B. 942, 98th Gen. Assem. Sess. Ill. 2013.

27. S. 515, 2013 Leg. Sess. Mass. 2013.

28. S.B. 667, 2014 Leg. Sess. Md. 2014.

29. H.P. 962, 126th Leg., 1st Reg. Sess. Sess. Me. 2013.
30. H.F. 76, 2012 Leg., 88th Sess. Sess. Minn. 2012

31. S.B. 226, 51st Leg., 1st Sess. Sess. N.M. 2013

32. A. 5389A, 2013-2014 Gen. Assem., Reg. Sess. Sess. N.Y. 2013.

33. S.B. 104 / H.B. 121, 130th Gen. Assem., Reg. Sess. Sess. Ohio 2013.

34. H.B. 2992, 77th Leg., Reg. Sess. Sess. Or. 2013.

35. S.B. 400, 2013 Leg. Sess. Pa. 2013.

36. H.B. 1085 / S.B. 5224, 63rd Leg., Reg. Sess. Sess. Wash. 2013.

37. S. 51, 2007-2008 Leg. Sess. Wis. 2007.

38. Bentley TG, Effros RM, Palar K, Keeler EB. Waste in the U.S. health care system: A conceptual framework. Milbank $\mathrm{Q}$. 2008;86(4):629-59.

39. Himmelstein DU, Jun M, Busse R, Chevreul K, Geissler A, Jeurissen P, et al. A comparison of hospital administrative costs in eight nations: US costs exceed all others by far. Health Aff (Millwood). 2014;33(9):158694.

40. Calfee JE. Pharmaceutical price controls and patient welfare. Ann Intern Med. 2001;134(11):1060-4.

41. Cubanski J, Neuman T. Searching for savings in Medicare drug price negotiations. Menlo Park, CA: Kaiser Family Foundation, 2016.

42. Pollack H. Medicare for All if it were politically possible would necessarily replicate the defects of our current system. J Health Polit Policy Law. 2015;40(4):923-31.

43. McDonough JE. Wyden's waiver: State innovation on steroids. J Health Polit Policy Law. 2014;39(5):1099-111.

44. Blumenthal D, Collins SR. Health care coverage under the Affordable Care Act-a progress report. N Eng J Med. 2014;371(3):275-81.

45. Corlette S, Volk J, Berenson R, Feder J. Narrow provider networks in new health plans: balancing affordability with access to quality care. Washington, DC: Georgetown University Center on Health Insurance Reforms, The Urban Institute; 2014.

46. Deber RB. Health care reform: Lessons from Canada. Amer J Public Health. 2003;93(1):20-4

47. Palmisano DJ. The danger of single-payer health insurance. Arch Internal Med. 2004; 164(20):2281-2.

48. Shaw JC. Oh, Canada: Comparing single-payer health care with practice in the United States. Am J Med. 2005;118(10):1064-6.

49. Thomson S, Osborn R, Squires D, Jun M. International profiles of health care systems, 2013: Australia, Canada, Denmark, England, France, Germany, Italy, Japan, the Netherlands, New Zealand, Norway, Sweden, Switzerland, and the United States. New York, NY: The Commonwealth Fund; 2013.

50. Mossialos E, Thomson S. Voluntary health insurance in the European Union. Brussels, Belgium: European Observatory on Health Systems and Policies; 2004.

51. Mossialos E, Wenzel M, Osborn R, Sarnak D. 2015 International profiles of health care systems. New York, NY: Commonwealth Fund; 2016.

52. Cubanski J, Swoope C, Boccuti C, Jacobson G, Casillas G, Griffin S, et al. A primer on Medicare: key facts about the Medicare program and the people it covers. Kaiser Family Foundation, Menlo Park, CA; 2015.

53. Gruber J. Proposal 3: Restructuring cost sharing and supplemental insurance for Medicare. Brookings Institute, The Hamilton Project, Washington, DC; 2013.

54. Hogan C. Exploring the effects of secondary coverage on Medicare spending for the elderly. Washington, DC: Direct Research, LLC; 2014. 